$\mathbb{T}$ periodica polytechnica

\author{
Social and Management Sciences \\ 18/2 (2010) 103 111 \\ doi: 10.3311/pp.so.2010-2.05 \\ web: http://www.pp.bme.hu/so \\ (c) Periodica Polytechnica 2010
}

RESEARCH ARTICLE

\section{Knowledge sharing in medical team: knowledge, knowledge management, and team knowledge}

\author{
Balázs Péter Hámornik / Marta Juhasz
}

Received 2010-07-14

\begin{abstract}
Nowadays medical work is team work of several professionals (like for example in rehabilitation) so knowledge is a central issue in this field: the fast growing biomedical knowledge base is needed to be applied as fast and as effectively as possible to avoid medical errors. The suitable method for this purpose is a knowledge management system, which is based on the specialties of medical knowledge, and the expert teams of physicians and related professionals. The aim of this article is to review the literature on three levels: (1) personal level (medical knowledge and knowledge encapsulation theory by Boshuizen and Schmidt (1992) (2) team level (medical teamwork, e.g. in rehabilitation); (3) and organizational level (knowledge management systems).

The medical work has some specialties that constraint the possibilities of knowledge management. On one hand, medical knowledge in a high level of expertise is activated faster, but in a less detailed manner compared to other domains of knowledge; it is stored in an encapsulated form. On the other hand, as a consequence of medical work, any effective knowledge management system must be "baked in" the daily routine (Devenport, Glaser 2002). The user interface must be on the spot, avoiding additional efforts, and time needs. As a conclusion, this review is the integration of experiences and results from group interaction researches in high risk environment, and the practices from the knowledge management applications in several domains of work and to find the theoretical possibilities of a successful knowledge management system in the medical field.
\end{abstract}

\section{Keywords}

medical team $\cdot$ knowledge $\cdot$ knowledge management $\cdot$ knowledge encapsulation $\cdot$ rehabilitation $\cdot$ team interaction

\section{Balázs Péter Hámornik}

Department of Ergonomics and Psychology, BME, 1117 Budapest, Magyar tudósok krt. 2, Hungary

e-mail: hamornik@erg.bme.hu

\section{Marta Juhasz}

Department of Ergonomics and Psychology, BME, 1117 Budapest, Magyar tudósok krt. 2, Hungary

e-mail: juhaszm@erg.bme.hu
The purpose of this study is to form a picture of knowledge, and knowledge management, focusing on the applied field of medicine and medical knowledge and teamwork to ameliorate the medical knowledge sharing, medical practice, and patient safety. At first the definition of knowledge and knowledge management is needed, then the review of the applicability of the knowledge management systems. Focusing on the medical field, the nature of medical knowledge and the development of medical expertise are of importance. From an extra-individual perspective the most important point is the necessity and advantages of medical teamwork and knowledge sharing. On the basis of these theoretical considerations, the study presents a functioning knowledge management system showing possibilities of applying such systems in Hungary, completed with teamwork development.

\section{Knowledge}

At the beginning of the general introduction of about the knowledge itself, it is important to review the cognitive psychological backgrounds based on the literature of the human memory. Knowledge as other long term memory contents is represented in different ways in the human mind. According to Tulving [18] there is an episodic and a semantic long term memory. This means the separation of a specific event and an experience related retrieval of memory contents (with context) form the general 'background knowledge', what is standing behind the experiences. For example the episodic memory refers to the specific treatment of a patient done by the physician. The semantic memory (the background knowledge) refers to the facts, and general knowledge about this patient's illness (learned from this case, or learned during the education, and free from the memories of specific experiences). Also an important dichotomy is the explicit-implicit classification of memory recall (and contents), which refers to the level of conscious access [18]. The frequently used expression of the implicit memory recall refers to the unconscious and unintended usage of these memory contents. The explicit memory refers to the conscious and intended memory retrieval. These classifications can be completed with the concept of the procedural memory [17] including the im- 
plicit memory described above, but it is also focusing on the body movement procedures and routine (work) practices (e.g. riding a bike, or doing a routine medical task that cannot be described easily in words).

It is also needed to define knowledge as a concept by distinguishing it from other (sometimes erroneously) related ideas, such as data and information [14]. Data are facts related to some specific events. To find gradual differences, it is better to see how information is defined: Information is data which are important for us, and these data are organized by our goals. Then the next level is knowledge, it is the closest to action. Knowledge is skills and information used for problem solving. It can also be defined organizationally [1]: knowledge is things that an employee needs to know to reach the most effective performance in the organization. Knowledge in organizations, as in individual cognition, can have an explicit form and a tacit form too.

Knowledge in the organization can be imagined in a hierarchical form, for example as a pyramid [11], [3] (see Fig. 1].

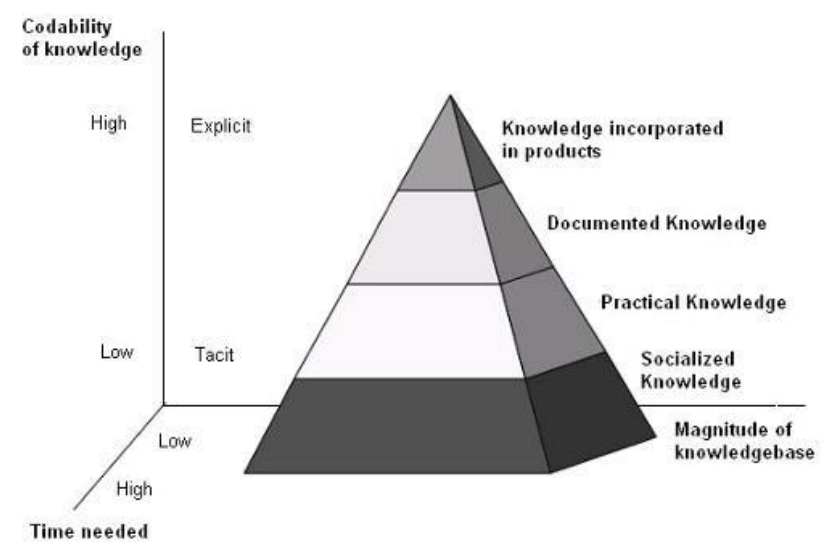

Fig. 1. Organizational knowledge pyramid $3 \quad 11$.

Unfolding the metaphor it can be said that the different levels of knowledge have different features in time need, amount, and encoding (from tacit to explicit). The knowledge pyramid consists of four levels: (1) socialized knowledge on the basis, which is the broadest, but consists of also the most tacit form, coming from the interrelations inside the organization. (2) On the second level there is practical knowledge, which is more explicit, but less broad. It mainly comes from the knowledge and the experiences of expert employees. (3) On the third level of the knowledge pyramid there is documented knowledge which is written in handbooks. It is explicit, but contains less knowledge than the lower levels. (4) The most explicit, but the narrowest level is knowledge incorporated in products. Upwards, the time needed to apply the different forms of knowledge is decreasing (e.g. it is a long time to get the knowledge together from the whole organization on the socialized level).

\section{Knowledge management}

The first step to knowledge management is the recognition of knowledge as the only real competitive-advantage of an organization [20]. That makes the need for developing "knowledge production". The direct antecedents of knowledge management comes from the cognitive science, and artificial intelligence research [20]. Knowledge, as a semantic memory structure can be incorporated in the products, and also incorporated in the power (social influence, organizational power as a leader's power). To sum up knowledge is a psychosocial phenomenon which has an effect on business. As a consequence knowledge and its management are needed to reach long term competitiveeffectiveness. In this point of view knowledge management is a consequence of strategic decision making [20]. The decision of the organization and the team concerns the knowledge needed in the future. Does the organization need new skills, or should the already existing set be better exploited? If new knowledge is needed, is it available in the organization or should external sources be involved? If the organization decided to start a knowledge management system, it is necessary to decide the form of the support of knowledge production, and sharing. Furthermore, it is also necessary to consider the organizational structure which is suitable for the knowledge management system.

\section{Approaches of knowledge management}

Knowledge management does not mean the same thing in different organizations, and it has several perspectives according to numerous experts and researchers. On the basis of a review of a segment of the literature, four main approaches can be distinguished in knowledge management studies (based on [12, 13]. The first point of view is the normative approach (1): it takes the knowledge management as an instrument of organizational competitiveness, which can build knowledge in the organization. From this point of view, management has an important role in the establishment and running of knowledge management systems. The second point of view on knowledge management is the sociological-institutionalist approach (2). It takes a completely different notion and attitude of knowledge management: that is a kind of "fashionable phenomenon" used for legitimating the management. As in all cases of scientific and business practices, at first there are exaggerated expectations against knowledge management ("it can solve any organizational problems"), then later, when it becomes clear that these expectations are too much, people become disappointed. As a consequence of the disappointment, the so-called "knowledge management fashion" falls off, then after a certain period, the fashion can rise up again to start the same line. The third perspective is the interpretativist-constructivist approach (3), which is despite its complex name simply claims that there is no knowledge transfer; there is only knowledge transformation among individuals. Knowledge can only be interpreted by individuals, and not transferred in the same form among them. From this point of view, 
culture, power and politics become important aspects. Then, the fourth and last perspective is the critical-postmodern approach (4). Matched with the postmodern thought of other fields (such as politics and philosophy), this approach states that there is an undercover ideological control (and personal thought control) behind knowledge management systems. By the application of such systems, it can be dictated what is right knowledge and what is not. It means knowledge management could function as an instrument of surveillance, and discipline.

The precondition of knowledge management systems also depends on the theoretical approach. From this side, it is also possible to distinguish four more perspectives of what knowledge management depends on [20]. The first form (1) is the instrumental point of view: fully functioning and effective knowledge management relies on a suitable IT (information technology) solution. From the managerial standpoint (2), knowledge management is a part of the organization's strategic human resource management (SHRM); mainly includes competency and talent management. It is also recognizable in the perspective that knowledge is defined as some content that only exists in people's minds (and not in a software solution). Looking at the conditions of knowledge management from a structural point of view (3): the main requirement for a successful knowledge management system is an organizational structure, and organizational culture. Finally, the liberal approach of knowledge management (4) preconditions claim that knowledge only exists in people's minds. Moreover, it is also claimed that this knowledge characterized by exclusive features is not manageable at all. In consequence, creativity is an important value, and it needs freedom, which is impossible because of the acting of the management.

The direct preconditions and practical steps of establishing a knowledge management system are the following [13]: first, make the organization aware that knowledge management is a competitive advantage; then plan a knowledge management strategy; make a knowledge management project, and finally execute it strictly. IT (Information Technology) based marketing, communication, and organizational culture are also needed for the supply of a knowledge management system.

Knowing the conditions of knowledge management, it is needed to consider the organizational constraints of a knowledge management system. After [13] survey on a Hungarian sample resulted three main problems that can hinder a knowledge management project, which are (1) the lack of knowledge management expertise, (2) the lack of acceptance of knowledge management, and (3) the lack of a fitting culture in the organization. In addition, time and money shortages are also important constraints of knowledge management. Plus, in this survey, the lack of the management's support, and the technological shortages also appeared as constraints.

Despite the latter constraints, if a knowledge management system comes to functioning, there are also three traps which can block its efficacy. According to [1] there are (1) management, (2) individual learning, and (3) IT traps menacing knowl- edge management systems. The first, the management trap (1) means that dominant and proactive management can make a knowledge management system ineffective. Particularly when knowledge management is administratively over-controlled, in spite of meeting the management's expectations, it is not effective. When it is too much constrained, then only the fully rational behaviour is accepted, there is no knowledge management needed, because the rationality implies the best knowledge on the place where it is needed. The individual learning trap (2) refers to a gap frequently occurring in knowledge management systems, namely when there are no transfer opportunities between individual learning (as a part of knowledge management), and organizational, common knowledge. As a consequence of this gap, the individually learned knowledge cannot even reach the organizational level. To solve this problem, the first step is breaking the knowledge-equivalent-to-power paradigm in the organization, if a person who owns special and needed knowledge can share it without the fear of losing his/her social status (or position). Finally, the third trap threatening the knowledge management systems (3) is the IT trap (the over usage of the IT solutions). If an organization only and solely uses an IT solution for knowledge management, all the explicit knowledge contents are included, but most of the implicit knowledge will be left out of the official "knowledge" that is managed by the system. This leads to the production of data and information, which is organizationally less useful, instead of real knowledge production. The solution for this problem may be the better fitting of the IT solutions to the culture to keep the knowledge in the social network context of the organization.

To ensure the success of a knowledge management system, it is important to match the individual perspectives with the organizational strategies (e.g. HR strategies) [20]. The fields of a knowledge management process are the following: education (different knowledge is needed for different tasks, and people may have heterogeneous knowledge too), organizational redesign (to reach a coherence in structure), information planning (to clearly know what is needed), and task distribution (to enhance cooperation). On the basis of this, knowledge management can also be defined as a process [13], which unfolds, produces, enumerates, conserves, shares, integrates the knowledge capital of an organization. Knowledge production is a circular process, as it can be seen on Fig. 2. New ideas are organized, and conserved, then shared in the company. This leads to the application of this new knowledge (e.g. in workshops), then new ideas turn up to make the same circle again [13]. The keyword of this knowledge production process is the synergy that produces innovation potential and added value.

\section{Knowledge and knowledge management in the med- ical field}

Medicine is a real high-risk environment in which a failure or an error can lead to serious consequences. That is why the newest knowledge must be applied in this domain, and that is 
Fig. 2. The process of knowledge production [13]

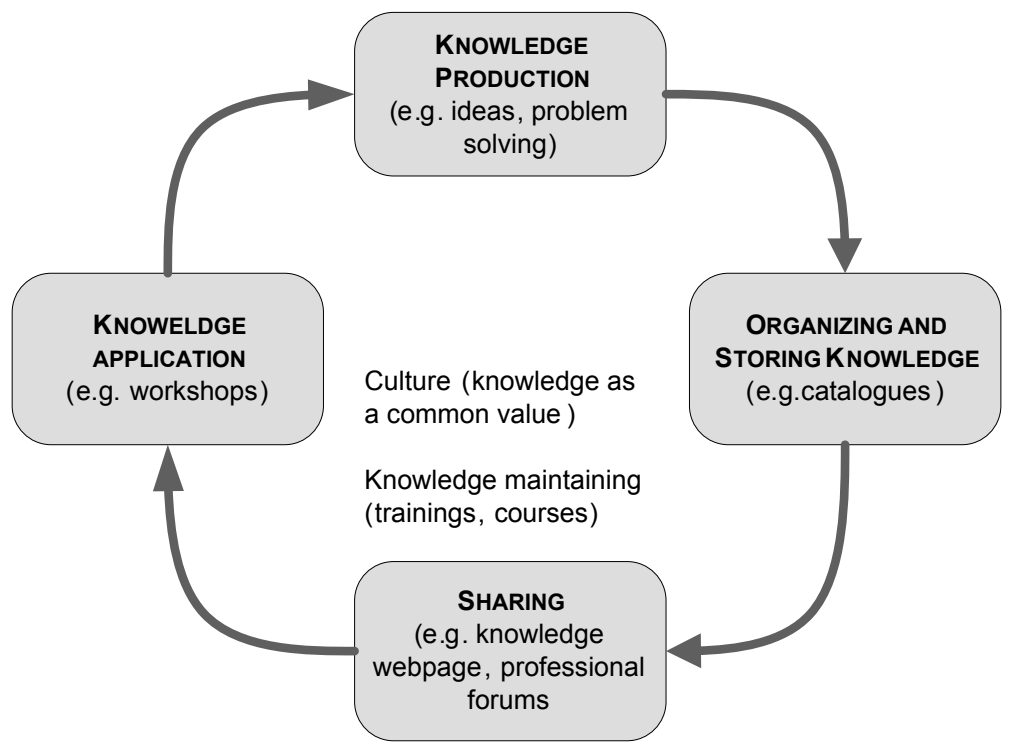

why knowledge sharing in such medical teams is important subjects of the contemporary team cognition research. Above the individual level, knowledge and its sharing are the content aspects of the shared mental models (SMM), which can also have a dominant effect on team performance. The shared mental model is a shared knowledge and reference between the team mates. It develops by the team communication, and contains shared representations about the current situation, about roles and responsibilities, and about the competencies [4]. At first, medical knowledge, and its specialties must be considered on individual and team level also, in order to make the sufficient foundations for any possible knowledge management systems in medical field.

\section{The medical knowledge on the individual level: its usage and features}

Medical practice heavily relies on two sources: on the experiences with the diseases, and their treatment on one hand. And it also relies on the prevailing theoretical explanations in the other hand. To find the balance and the right interactions between these two sources is a key of successful treatment and safety in medicine. The theoretical explanations are part of the medical knowledge contributing to the understanding of the human body's functioning and its dysfunctions [19].

The medical background knowledge is growing day-by-day: it doubles its amount by every 19 year [10]. It is increasingly fast, comparing even to the general human knowledge growth, which doubles itself by every 33 year.

Cognitive psychology research covered this field in the 1970s to explore the role of medical knowledge in clinical problem solving. So these first cognitive psychological researches focused on the individual semantic level, and researched the problem solving of medical students and experts in diagnoses, using think-aloud or recall studies [9,16]. The ordinary problem solving cognitive process can be identified in diagnosis making: seeking a general diagnostic hypothesis, then searching for ad- ditional information (or background knowledge) to confirm or refuse this hypothesis. It was generally found that experts have more accurate diagnostic hypotheses than students that can be explained by their broader domain specific knowledge [19].

Nowadays, like in other high-risk fields team processes, and team work are emphasized, so knowledge sharing has come into focus. Following the previously used perspective, this article at first reviews the individual semantic level (the development, and form of medical knowledge), then takes the team perspective into account (knowledge management in medical teams, needs for better team cooperation).

The medical field has the occupational psychological features of a high risk work environment (like nuclear power plants' operator teams, or military operation teams have), that includes high workload, and taskload, and high probability of negative consequences (for example life danger) of erroneous decisions. In such circumstances the researches turned the focus on the specialists' learning and knowledge structure to provide the conditions of the effective lifelong learning, and to avoid errors, and enhance patient safety, and make the medical work more effective. Based on the cognitive psychological researches of the 1970-80s about the role of medical knowledge of medical expertise three different views have developed. The first point of view gives a central role to medical knowledge in diagnosis making. In this view, the lack of background knowledge, for example the lack of deep understanding of anatomy can directly lead to clinical errors [19]. Therefore, clinical knowledge (and practice) fully depends on medical knowledge. From the second view, medical and clinical knowledge function like two worlds apart: these two have their own knowledge bases and structures. Clinical knowledge aims to solve problems, relating symptoms to disease categories and treatments (producing direct clinical associations). Medical knowledge indeed, contains general principles about the human body, organized into causal chains to provide more coherent explanations [19]. If there are two opposite theories in psychology, one claiming that there is 
a hierarchical relation between medical and clinical knowledge, the other claiming that there is no such relationship, a theoretical integration comes as "aurea mediocritas" styled third point of view. [2] claim that medical knowledge has an important (but not sole) function in the development of easily applicable clinical knowledge. This third point of view, Knowledge Encapsulation Theory states that a detailed network of medical knowledge is packed or encapsulated below a smaller number of higher level concepts. These higher level concepts of declarative memory have the same explanatory power as the whole network had before being encapsulated in it. Thinking about knowledge as an associative network it can be stated that these encapsulated knowledge packages can be directly activated, and it ensures fast understanding. Before starting medical school, lay people have an erroneous common knowledge network about illnesses. In medical school, this semantic network is corrected, and modified. And also a huge amount of new, detailed medical knowledge (anatomy, chemistry, physiology) is added, which extends the network. Starting the internship in medical education (the $5^{\text {th }}$ year in the European curriculum) medical knowledge (organized by schemata) becomes tuned by the cases encountered during practice [19]. After a certain time of practicing, the encapsulated knowledge structures become stronger in the experts' knowledge network of interconnected associations, than the outwards content connections. The beginner medical students naturally use fewer concepts in their diagnostic explanations, than the intermediate level students, who have just started internship, thus they have the most detailed semantic network of medical knowledge (incorporating what they have learned in school, and during their practice). Experts, who have been practicing for years, have less detailed medical knowledge. But this less detailed network contains encapsulated knowledge structures developed during the years of practice. These knowledge encapsulations contain the detailed medical knowledge in a compact form, that can be unfold when it is needed, so this can lead to faster but also correct decisions, and diagnoses. The described phenomenon is called Intermediate Effect by [16] and is also supported by diagnoses recall the research of [19].

The knowledge encapsulation theory is a scheme-based cognitive theory of semantic knowledge in the medical field: scheme-based developing of the organization of medical knowledge is the key point of fast and safe diagnostic reasoning. There is a chunking process of disease features, to keep the knowledge content in applicable format: if the new information (or knowledge to be stored) reaches a limit, a new scheme comes to existence instead of modifying the old one. This process, as in other fields of problem solving, secures the reasonable effort investment for the case to be diagnosed. It is important to note that the encapsulation process goes on during the practice for medical education. That can make the medical practice more important in the curriculum in order to enhance knowledge encapsulation.

As in general, the cognitive organisation of mind is more than a collection of semantic structures of knowledge. Above the semantic level (the knowledge about the world or about the illnesses, treatments) there are important episodic level cognitive contents too. The episodic level is containing the timeand location specific, unique, and personally experienced memories of events, for example the treatment of a specific illness of a given patient, and experiences of solving a medical problem. Knowledge encapsulation also includes episodic, scriptlike memory contents: illness-scripts. As a broadening of the theory it can be said that illness-scripts are higher than semantic knowledge structures: they are the transition of knowledge from the causally organized networks to a narrative structure which is stored as episodic memory content [19]. Illness scripts are one step further than encapsulated knowledge: they also contain patient background factors, signs, symptoms, and the ways of treatment strongly linked. They develop by diagnoses, patient treatments, which leave episodic traces referring to the final causes or diagnoses, and also to the encapsulated knowledge.

As it can be seen on Fig. 3, there is an order and hierarchical difference between the encapsulated knowledge and the illness scripts: the encapsulated knowledge is included in the illness scripts, and completed with practical experiences, case history to become a narrative structure referring to the right diagnoses and treatment.

To summarize the theory of knowledge encapsulation, it is necessary to assign the role of it. Medical knowledge, as semantic memory content is used as a basis of individual decision making processes. This content is encapsulated during the practice while the student is becoming an expert. By the development of the illness scripts, this knowledge is linked to episodic memory content (the exact cases encountered), that helps to make the decision making faster and safer. It is only an individual level of investigation, but as nowadays in most of the fields, medicine is turning to teamwork. Knowledge is strongly linked to medical teams, knowledge sharing, and knowledge management.

The application of this theory can appear in medical teams or in other expert teams, for example the interdisciplinary medical rehabilitation teams. The level of expertise (beginner, intermediate, and expert levels) and the structure of applicable knowledge may affect the team mate's (a doctor's or a physiotherapist's) diagnoses and decisions, and also it may affect the interactions between the team mates.

\section{The team level of medical knowledge: Teamwork, and the characteristics of the medical team work}

The team is the defined place of knowledge sharing, and common knowledge application using a shared mental model to solve a problem. Working in teams is now quite common in medicine, which opens the possibility of comparison between other high-risk areas such as aviation, or nuclear power plants. The most examined areas of medical team interaction are surgery, and anesthesia. However, there are several other domains where cooperation has a growing importance, such as nursery, and rehabilitation. These are non-emergency fields 


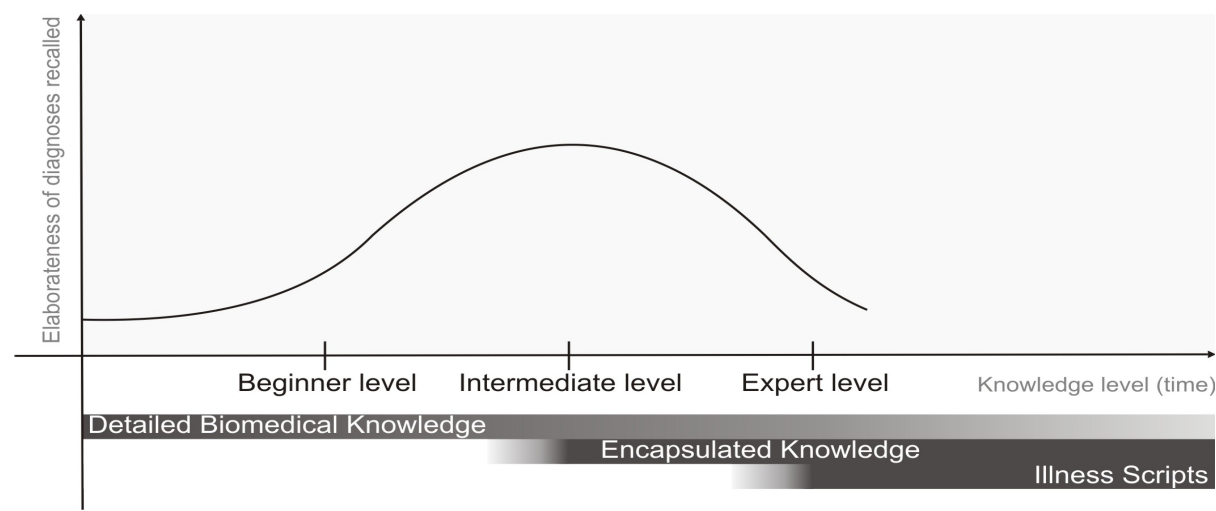

Fig. 3. The schematic figure of the development of encapsulated medical knowledge and illness scripts across the knowledge levels of becoming an expert (based on the review of the conclusions of diagnoses recall studies 19

compared to surgery, intensive care, or anesthesia, but the responsibilities, and the risks are as high there as in the case of the former, moreover, interdisciplinary cooperation has a central role in teamwork.

In a team setting, communication can be regarded as "information engineering" or a social constriction perspective [6]. In the first point of view the main cause of communication breakdowns is the "noise", and the goal is to reduce this "noise" to make the messages transmitted. From the second perspective, the communication is embedded in a structure that has important qualities regarding the communication. The social context, like the status hierarchy, may influence people on how to communicate and collaborate [6]. The specificity of medical teams mainly comes from the urgency of the tasks (human lives are in danger), and also from the rising complexity of their work, that leads to the presence of an amount of knowledge in the system almost unbearable [6].

In medical teams, compared to aviation [8], there is less implicit communication, that is a sign of a developed shared mental model. However, if compared to aviation, in medicine there are fewer procedural rules. Doctors, or other medical experts have a larger degree of freedom in their (treatment) decisions, in turn it is also the consequence of the extend common ground of shared implicit rules and knowledge [8]. According to the ratio in medical curricula (e.g. [7]) on rehabilitation medicine curricula in Central Europe), technical skills are taking the central role in team communication, and non-technical skills are underrepresented. Also medical teams compared to other groups in high-risk environments, have a more hierarchical structure. For example, there is an important status difference between doctors and nurses, and that influences their communication too, as it leads to decreased horizontal communication and less heedful interrelating [22]. The hierarchy also makes the leadership behaviour more emphasized [8]. These characteristics have an effect on shared cognition, and on knowledge and sharing of medical teams. There are three ways to develop teamwork and its efficacy, which is valid for medical teams too [6]. At first, it is important to help the raising of shared situational aware-
Below the horizontal axes, the three differently shaded stripes are representing the development of the tree different knowledge structures by the progress of the knowledge level.

ness including the case, and the context. Then it is needed to refresh and update the team's understanding of the (frequently changing) context. Specifically, it leads to the development, and updating of a shared mental model in the mind of the team members. Finally, it is necessary to develop the team members' capacity for heedful interrelating to make them acting with each other's and the team's perspective in mind [21]. These ways of development could appear in the organizational structure in the motivation system, knowledge management, and team meetings to reach effective healthcare communication [8].

\section{The example of rehabilitation}

In medical education, the opportunities to learn the skills of effective teamwork, such as communication, cooperation, and leadership generally are missing. Taking the example of rehabilitation into consideration it can be said that disability can cover several parts of the body, and several fields of life, therefore rehabilitation has to address all the needs of the patient to maximize the functional and psychological abilities, and to improve the quality of life. These goals are beyond the possibilities of one physician, therefore other rehabilitation professionals and also the patient or client need to be involved in the rehabilitation teamwork [7]. The composition of a rehabilitation team is determined by the patient's type. But a general expectation for team members is that they need to be loyal, and problem-oriented rather than status-oriented, and they also need to be cooperative, supportive and aware of each others' roles to be able to understand the professional boundaries and respect the others' skills, to recognize the professional and personal limitations, and they need to be ready to learn from other team members. It is the leader's task to clarify the team roles. The last three expectations concerning respect and recognition of professional skills and limitations, openness to learning are parts of heedful interrelating [21]. In the rehabilitation process the following professionals are usually included in the expert team [7]; and [9]: rehabilitation physician, rehabilitation nurse, physiotherapist, occupational therapist, speech/language therapist, social worker, clinical psychologist, prosthetist. These professionals have dif- 
ferent types and levels of qualification, therefore they have different places in the hierarchically organized medical team.

In the field of rehabilitation, there are two models of teamwork, for different professionals working for the same goal [7]. The (1) multidisciplinary approach provides a centralized model of team construction: each professional conducts the assessment and the treatment individually, and communicates with the team leader, who coordinates, and distributes the information produced. Contrarily (2) the interdisciplinary approach emphasizes joint problem formulation, and solution. This approach includes more frequent consultation, which leads to a detailed shared mental model of the patient and his/her social context in the teammates' mind. Because the interdisciplinary approach reinforces the synergy more, it can be seen as the preferred model of rehabilitation teamwork [7]. Taking a general perspective from direct client service professions the client must be taken into account as an active and informed member of the team. The professionals should know how to communicate and cooperate with the client. It does not differ from the field of rehabilitation medicine in a great degree, especially in goal setting, and treatment planning [7].

Teamwork difficulties are mostly based on communication problems as team members are educated differently, and they communicate differently. They consider cooperation from different perspectives, form different levels of hierarchy, or different sides of the gender gap [7]. Team hierarchy also appears in the responsibilities: generally the physician is responsible for the whole rehabilitation process of the patient; therefore they usually act as leaders. To ameliorate teamwork, in which communication and knowledge sharing are prioritized, it is necessary to develop leadership skills, and communication skills [7]. It enhances the knowledge of the different roles, and professions, and it can lead to more elaborated shared mental models of the cases. In this point, the experiences and methods of teamwork improvement from aviation, nuclear power plant, or other highrisk fields must be taken into account. In education as well nontechnical skill trainings, common points of curricula, and joint clinical experiences can be useful to enhance the teamwork competencies of the future rehabilitation team members.

\section{Possibilities of a knowledge management system in the medical field}

As it is emphasized above, the knowledge needs of the healthcare system has become almost unbearable [6], and the physicians are almost unable to memorize this amount of information and knowledge [10]. The growing quantity of knowledge and information in the medical field is not just a theoretical question, but a serious problem of life or death [5]. That is why the general goal of teamwork innovation and knowledge management is to treat this information overload. The overload of information and knowledge is in correlation with medical errors, useless examinations, and failures of medication which leads to higher costs [5]. It is harder to introduce a knowledge manage- ment system in a field with almost the highest knowledge needs, and also the physicians' traditionally broad freedom of decision can also be a brake of change. The key is time pressure, partly generated by the information overload, and by the danger of life in emergency fields. Therefore to make the knowledge management system effective, the right knowledge must be given right on time, on the spot, and not after the situation, because usually there is no time left to search for information post hoc [5]. The realization of such systems strongly depends on the interface used [10]: nowadays naturally it must be a computer based tool, with easy-search facilities, that minimizes the time and the effort to be used for information seeking. These features can help the latest information to be involved in medical practice, because a knowledge management system fitted to the tasks, is not any more time-consuming. The usability of a system described above, depends on the amount of search time (searching for sources, or for data), the accuracy of results and on subjective factors like satisfaction with the decision (based on the new information), the effort used on the search, the cognitive load during the usage of the knowledge management system, and the time saved by the useful new knowledge [10]. If the physician or nurse has to do some extra efforts surplus the normal daily routine, it reduces the amount of new knowledge built in the decisions. That is why the early knowledge management attempts failed in the medical domain. The key of success is the fact that specific, new knowledge should be "baked in" the routine tasks, then it becomes inevitable [5]. As a consequence of this the knowledge management system should be built into the generally used application, as a part of the everyday activities of patient care.

The well-known example of a successful knowledge management system is the one applied in the Partners Healthcare's hospital in Boston, US [5]. By the millennium a knowledge management system had been introduced in this hospital to help and improve the decision making of physicians with a technological change, and by providing up to date clinical knowledge. First, the advisory application was integrated into the order entry system, which is used for ordering examinations and medications. Then the patient database was also connected to the knowledge management system. Therefore the physician could follow up the patient's examinations, ongoing medications, further review dates. Also the system verifies the decisions of the user by questions, and recommendations, that can be overwritten only with explanation. So this solution respects the medical experts' freedom of decision. All these features function real time, during the normal usage of the order entry or the patient database system. In uncertain cases, the user can also launch a conference call to ask other experts in different hospitals around the world. This is completed by a database called "the handbook", which contains the latest medical knowledge, books, journals, online databases selected by the leading experts of Partners Healthcare. Because these contents are provided in an effortlessly usable format, the handbook could become popular among physi- 


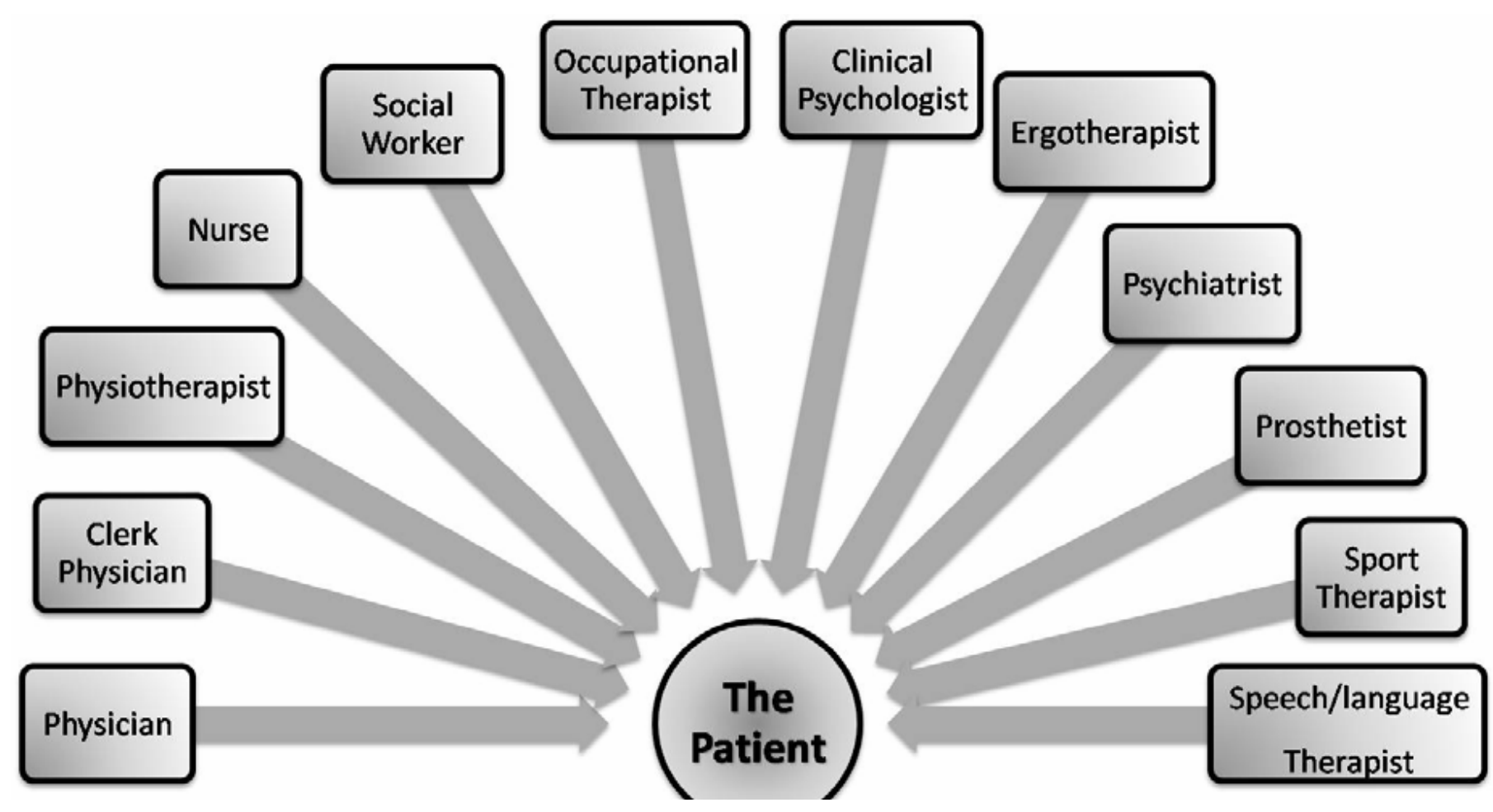

Fig. 4. The professionals included in the rehabilitation team $\sqrt{9}$

cians. This knowledge management system's positive effect is the decrease of medical failures by $55 \%$, and the increase of choosing the right medication at the first time to $81 \%$. It must be taken into account that the introduction of such a knowledge management system is a long process, for Partners Healthcare it almost took 10 years to reach these results. But it is not only saving lives, but saving money too, by the decrease of errors and shorter hospitalizations. The key points in the success of this knowledge management are real time functioning, interconnected order entry, patient database, follow up, decision support, and that knowledge base (handbook) systems are all available in one interface. It should be emphasized that the system only gives recommendations, so it respects the experts' knowledge, allows to combine their own decisions with the recommendations to involve the new knowledge in the decision.

\section{Conclusions and future perspectives}

The article provides a review of the possibilities of the application of knowledge management in the medical field. First defining the knowledge, than summarizing the advantages of knowledge management and the constraints, the review focuses on the specificities of medical knowledge. At first, the knowledge is organized differently in physicians' mind from those in other experts': it is encapsulated on the expert knowledge level [16], [19]. The large amount of medical knowledge is compressed into knowledge packages, that can be used in diagnosing without unfolding them, but if it is needed (e.g. un unusual cases) the encapsulations can be unfold correctly into details. This way, the expert knowledge, and the use of this knowledge, including the encapsulations lead to fast and correct diagnoses.
Shifting from the individual level to the team level; comparing to other high-risk fields, in medicine, teamwork has the same importance as in aviation, or nuclear power plants. In a knowledge management system, the following three aspects must be taken into account: the specificity of medical teams [8], the possible ways of improving medical teamwork [6], and the specificities of medical knowledge described above. Knowledge in such professions is also team knowledge, distributed, or shared in the group. Therefore an effective knowledge management system must fit to the needs of teamwork in medicine. The medical field is a typical example of lifelong learning to maintain the highest level of healing, and to make this process effective the features of medical knowledge and the features of medical (or interdisciplinary) team interactions must be take into account. The effective team interaction and knowledge sharing (combined with information sharing also) may lead to better patient safety, and to a more effective medical work.

As an example it is shown that rehabilitation medicine [7], is a typical multidisciplinary field, where effective teamwork and cooperation should play a central role in reaching the rehabilitation goal. Compared to other medical, or even to other high-risk fields (surgery, nuclear power plant, aviation), rehabilitation is a non-emergency domain. It can be an advantage for a research field, and for developing a new team based medical knowledge management system.

Medical domain is still a stressful, and time pressured field: so the time consuming, extra effort claiming knowledge management systems were not successful in this field. To fit knowledge management to the specific needs of medical work, that is 
why our example, the Partners Healthcare's program is effective [5]. The main advantages are the right-on-time, right-on-thespot function of the system: it is integrated into the daily used order entry system, and patient database. The respect of the freedom of decision, and the time or effort saving qualities made the contents (e.g. the "handbook") popular among physicians, and made the latest medical knowledge involved in daily routine decisions.

As it can be seen medical knowledge is structurally different from the others, so a different knowledge management system is needed for the field. Knowledge management systems used in business and other knowledge-jobs are not applicable in an identical form. Instead, a bottom up approach of exploration and design is the most promising way of development. The approach could be based on team cognition, communication, and safety researches in aviation, nuclear power plant, or on medicine domain experiences and results (e.g. [15, 22]. The research and improvement of team interaction can be connected to a knowledge management system development perspective for medicine in the future. It means that three levels of thinking must be regarded: individual knowledge level (e.g. encapsulated and applicable medical knowledge), team level (e.g. interdisciplinary teamwork of experts), and organizational level (knowledge management, the accumulated, and needed knowledge for safe and effective patient care). The results of researches of group interaction in high-risk environments can be integrated into knowledge management applications' experiences (both from the business, and the medical domain) to develop a suitable knowledge management system for the medical field. For this process of research, development, and testing, the non-emergency rehabilitation medicine field can be promising. A link can also be made between individual knowledge, team interactions, and organizational knowledge which finally leads to better safety in treatments, and patient care.

\section{References}

1 Adair K, Knowledge managenement: a misjudged instrument of strategic change?, Organization, 11(4), (2004), 565-574, DOI $10.1177 / 1350508404042368$.

2 Boshuzien H P A, Schmidt H G, On the role of biomedical knowledge in clinical reasoning by experts, intermediates and novices, Cognitive Science, 16, (1992), 153-184, DOI 10.1177/1350508404042368.

3 Boutellier R, Gassman O, von Zedtwitz M, Managing global innovation, Springer, 2000, ISBN 978-3-540-25441-6.

4 Cooke N J, Salas E, Cannon-Bovers J A, Stout R, Measuring team knowledge, Human Factors, 42, (2000), 151-173.

5 Devenport T, Glaser J, Just-in time delivery comes to knowledge management, Harvard Business Review, 80(7), (2002.), 5-9.

6 Eisenberg $\mathbf{E}$, The social construction of healthcare teams, Improving healthcare team communication. Building on lessons from aviation and aerospace (Nemeth C, ed.), Ashgate Publishing, 2008., 9-20.

7 Eldar R, Marincek C, Kullmann L, Need for rehabilitation teamwork training in Europe, Croatian medical journal, 49(3), (2008.), 352-357, DOI 10.3325/cmj.2008.3.352.

8 Grote G, Zala-Mező E, Group interaction in high risk environment of the
Daimler-Benz-Foundation, Swiss Federal Institute of Technology, Zurich, 2004.

9 Hámornik B, Juhász M, A team-munka szerepe a rehabilitáció orvosi munkában [The role of teamwork in medical practice ], A foglalkozási rehablitáció támogatása pszichológiai eszközökkel [The Support of Vocational Rehabilitation by Psychological Tools] (Juhász M, ed.), Typotex, 2010.

10 Heathfield $\mathbf{H}$, Louw G, New challenges for clinical informatics: knowledge management tools, Health Informatics Journal, 5(2), (1999), 67-73, DOI $10.1177 / 146045829900500203$.

11 Lengyel B, A tudásteremtés lokalitása: hallgatólagos tudás és helyi tudástranszfer. [The locality of knowledge production: Tacit knowledge and local knowledge transfer], Tér és Társadalom, 18(2), (2004.), 1-21.

12 Móricz P, Drótos G, Gelei A, Kováts G, A tudásmenedzsment témaköreinek kutatása és oktatása a BKÁE Vezetési és Szervezési Tanszékén [The Research and Education of Knowledge Management in University of $B K A ́ E]$, Hol tart a tudásmenedzsment Magyarországon c. workshop MTA Vezetés- és Szervezéstudományi Bizottsága Tudásmenedzsment Albizottság [On Which Stage is the Knowledge Management in Hungary - Workshop Organized by the Hungarian Academy of Sciences] (Budapest, Hungary, 2004).

13 Noszkay E, Hol tart a tudásmenedzsment Magyarországon? [On Which Stage is the Knowledge Management in Hungary?], Gazdaságinformatikai Kutatási és Oktatási Fórum Szakmai Szervezetének Szakfolyóirata, 3(5), (2004.), 44-50.

14 Pakucs J, Papanek G, Innováció menedzsment kézikönyv [Handbook of Innovation Management], Magyar Innovációs Szövetség, Budapest, 2006.

15 Pronovost P J, Holzmueller C G, Rosenstein B J, Kidwell R P, Haller K B, Feroli E R, Sexton J B, Rubin H R, Evaluation of the culture of safety: survey of clinicians and managers in an academic medical center, Quality and Safety in Health Care, 12(6), (2003), 405-410.

16 Rikers R, Schmidt H, Boshuizen H, On the Constraints of Encapsulated Knowledge: Clinical Case Representations by Medical Experts and Subexperts, Cognition and Instruction, 20(1), (2002), 27-45.

17 Squire R, Declarative and Nondeclarative Memory: Multiple Brain Systems Supporting Learning and Memory, Journal of Cognitive Neuroscience, 4(3), (1992.), 232-243, DOI 10.1162/jocn.1992.4.3.232.

18 Tulving E, Concepts of memory, The Oxford Handbook of Memory (Tulving E, Craik F, eds.), Oxford University Press, 2000., 33.

19 van de Wiel M, Knowledge encapsulation. Studies on development of medical expertise, Dissertation, University of Maastricht, 1997.

20 van Engers T, Knowledge management: The role of mental models in business systems design, Dissertation, University of Amsterdam., 2001.

21 Weick K, Roberts K, Collective mind in organizations: Heedful interrelating on flight decks, Administrative Science Quarterly, 38(3), (1993.), 357381.

22 Yule S, Flin R, Paterson-Brown S, Maran N, Rowley D, Development of a rating system for surgeons' non-technical skills, Medical Education, 40(11), (2006), 1098-1104, DOI 10.1111/j.1365-2929.2006.02610.x. 